\title{
Adsorbent for Arsenic(V) Removal Synthesized by Radiation-Induced Graft Polymerization onto Nonwoven Cotton Fabric
}

\author{
Hiroyuki Hoshina $^{1 *}$, Makikatsu Takahashi ${ }^{2}$, Noboru Kasai ${ }^{1}$, Noriaki Seko ${ }^{1}$ \\ ${ }^{1}$ Environment and Industrial Materials Research Division, Quantum Beam Science Directorate, \\ Japan Atomic Energy Agency, Takasaki, Japan \\ ${ }^{2}$ ERH Techno Research Co., Ltd., Takasaki, Japan \\ Email: "hoshina.hiroyuki@jaea.go.jp
}

Received July 29, 2012; revised September 2, 2012; accepted September 10, 2012

\begin{abstract}
A fibrous adsorbent for arsenic (As) removal was synthesized with nonwoven cotton fabric as a trunk polymer. 2-hydroxyethyl methacrylate phosphoric acid monomer which composed of phosphoric acid mono $(50 \%)$ and di $(50 \%)$ ethyl methacrylate ester was introduced with radiation-induced graft polymerization onto nonwoven cotton fabric. The degree of grafting of $130 \%$ was obtained at irradiation dose of $20 \mathrm{kGy}$ with $5 \%$ of monomer solution for 2 hours reaction time at $40^{\circ} \mathrm{C}$ reaction temperature. After the grafted material was contacted with $10 \mathrm{mmol} / \mathrm{L}$ of zirconium $(\mathrm{Zr})$ solution at $\mathrm{pH} 1,0.38 \mathrm{mmol} / \mathrm{g}$ of $\mathrm{Zr}$ was loaded on phosphoric units as a functional group for $\mathrm{As}(\mathrm{V})$ removal. The resulting adsorbent was evaluated by column mode adsorption with $1 \mathrm{mg} / \mathrm{L}$ of $\mathrm{As}(\mathrm{V})$ solution at various $\mathrm{pH}$ with space velocity $200 \mathrm{~h}^{-1}$. The maximum capacity of $\mathrm{As}(\mathrm{V})$ adsorption was $0.1 \mathrm{mmol} / \mathrm{g}$ at $\mathrm{pH} 2$.
\end{abstract}

Keywords: Arsenic Removal; Cotton; Radiation-Induced Graft Polymerization; Phosphoric Acid; Zirconium

\section{Introduction}

The impact of water pollution by toxic metals on human health remains a significant problem throughout the world. Arsenic (As), which is one of the most common causes of water pollution, exists in high concentrations in natural water such as rivers, hot springs, groundwater and drainage from abandoned mines [1-4]. To solve the problem, a coagulation and ion-exchange of granular resin have been extensively used for removal of $\mathrm{As}(\mathrm{V})$ from water [5-6]. However, a large amount of waste is produced by water treatment with coagulation, and it is difficult to remove $\mathrm{As}(\mathrm{V})$ to a low concentration rapidly with these techniques. Hence, a new adsorbent which could effectively remove $\mathrm{As}(\mathrm{V})$ from water is needed.

Zirconium $(\mathrm{Zr})$ has been used for adsorption of $\mathrm{As}(\mathrm{V})$ as a functional group [7,8]. The reason is $\mathrm{Zr}(\mathrm{V})$ has a particular affinity for $\mathrm{As}(\mathrm{V})$. But $\mathrm{Zr}(\mathrm{V})$ could not be directly introduced onto polymeric materials. Phosphoric group has high affinity against metal such as $\mathrm{Fe}, \mathrm{Mo}$, Co and $\mathrm{Zr}$. Especially, $\mathrm{Zr}(\mathrm{V})$ strongly binds with phosphate at high concentration of nitric acid. Therefore, phosphorric group was introduced onto polymeric materials to load $\operatorname{Zr}(\mathrm{V})$. Then the strongly bound complex of phos-

${ }^{*}$ Corresponding author. phoric- $\mathrm{Zr}(\mathrm{V})$ shows high adsorption capacity of $\mathrm{As}(\mathrm{V})$, which means $\operatorname{Zr}(\mathrm{V})$ plays a role of intermediary in the adsorption process.

Radiation-induced graft polymerization (RIGP) is a useful method to introduce a functional group onto polymeric materials. The advantages of this method are rapidly creating radicals in a trunk material by irradiation without any chemical reagents and easily introducing functional groups onto a trunk material without signifycant changes in the properties of the trunk material $[9$, 10]. The fibrous adsorbent, which was synthesized by RIGP, can rapidly remove and effectively recover metal from water. Therefore, many types of adsorbent have been produced with RIGP. Normally these adsorbents were synthesized by using petroleum materials such as polyethylene and polypropylene as a trunk material [11-13]. Graft polymerization using cotton, which one of plant-based material, as a trunk polymer is possible to decrease petroleum resources dependence and contribute to conserving resources.

In this study, the Zr-type adsorbent for As(V) removal was synthesized by RIGP with a phosphoric monomer onto a nonwoven cotton fabric and was subsequently modified with $\mathrm{Zr}(\mathrm{IV})$ loading on phosphoric units. The adsorption behavior of the Zr-type adsorbent with $\mathrm{As}(\mathrm{V})$ 
was investigated by column mode adsorption.

\section{Experimental}

\subsection{Materials}

A nonwoven cotton fabric purchased from Marusan Industry Co., Ltd. was used as a trunk polymer. Phosphoric acid monomer (2-hydroxyethyll methacrylate phosphoric acid; Kyoeisha Co.) was used for grafting monomer which was composed of the mixture of mono (50\%) and diester $(50 \%)$ as shown in Figure 1. Zirconium sulfate tetrahydrate and Di-sodium hydrogen arsenate heptahydrate were supplied by Kanto Chemical Co., INC. All other chemicals and solvents were used without further purification.

\subsection{Graft Polymerization}

The nonwoven cotton fabrics were cut into $3 \mathrm{~cm} \times 5 \mathrm{~cm}$ and were packed in a polyethylene bag under nitrogen atmosphere, which were irradiated with electron beam at beam energy of $2 \mathrm{MV}$ and current of $3 \mathrm{~mA}$ under dry-ice temperature. The irradiated fabrics were placed into a glass ampoule and were evacuated. The aqueous emulsion of phosphoric acid monomer was transferred into the ampoule. The reaction temperature was maintained in water bath at $40^{\circ} \mathrm{C}$ and $50^{\circ} \mathrm{C}$. After graft polymerization, the grafted materials were washed several times with pure water and dried in vacuum oven at $30^{\circ} \mathrm{C}$. The degree of grafting (Dg) was calculated by the following equation;

$$
\operatorname{Dg}[\%]=\left(W_{1}-W_{0}\right) / W_{0} \times 100
$$

where $W_{0}$ and $W_{1}$ are the weights of nonwoven cotton fabrics before and after graft polymerization, respectively.

\subsection{Loading of Zirconium on Phosphoric Units}

$\mathrm{Zr}$ (IV) was loaded on phosphoric units by the contacting of $\mathrm{Zr}(\mathrm{IV})$ solution with a column. The grafted materials were packed into the column with an internal diameter of 1 $\mathrm{cm}$. The height of grafted materials in the column was 0.3 $\mathrm{cm}$. The $\mathrm{Zr}(\mathrm{IV})$ solution was prepared by dissolving Zirconium sulfate tetrahydrate in pure water. The $\mathrm{pH}$ of $\mathrm{Zr}(\mathrm{IV})$ solution was adjusted to $\mathrm{pH} 1$ and $\mathrm{pH} 2$ by addition of nitric acid. The $\mathrm{Zr}$ (IV) solution was delivered up-flow to (a)<smiles>C=C(C)C(=O)OCCCCOP(=O)(O)O</smiles>

(b)<smiles>C=C(C)C(=O)OCCCOP(O)O</smiles>

Figure 1. Chemical structure of phosphoric acid monomer: (a) mono ester; (b) diester. the column at flow rate of space velocity (SV) $200 \mathrm{~h}^{-1}$ using a peristaltic pump [Advantec, AP-1600]. After $\mathrm{Zr}(\mathrm{IV})$ loading, the adsorbent in the column was washed with pure water.

\subsection{Arsenic Adsorption}

To evaluate the adsorption performance for $\mathrm{As}(\mathrm{V})$, the adsorption test was investigated by column mode test. The solution of As(V) was prepared by dissolving disodium hydrogen arsenate heptahydrate in pure water. The $\mathrm{pH}$ of $\mathrm{As}(\mathrm{V})$ solution was adjusted with nitric acid and ammonia solution. These solutions were pumped into the column at various flow rates and were collected by the fraction collector. The concentration of $\mathrm{As}(\mathrm{V})$ was determined by induced coupled plasma atomic emission spectroscopy [ICP-AES, Perkin Elmer Inc.,Optimaa $4300 \mathrm{DV}]$. The breakthrough point was defined as the bed volume $(\mathrm{BV})$ of feed solution at $\mathrm{As}(\mathrm{V})$ concentration in the effluents reached $5 \%$ of that in the feed solution. The characteristic of breakthrough was observed by plotting $\mathrm{C} / \mathrm{C}_{0}$ which was the value of effluent dived by the feeding concentration against $\mathrm{BV}$, where $\mathrm{C}_{0}$ and $\mathrm{C}$ are the concentration of $\mathrm{As}(\mathrm{V})$ in the feeding solution and in the effluent, respectively.

\section{Result and Discussion}

\subsection{Graft Polymerization}

In order to minimize the mechanical damage of cotton fabric from irradiation, the graft polymerization of phosphoric acid monomer was carried out at irradiation dose of $20 \mathrm{kGy}$. Figure 2 shows the effect of reaction time on $\mathrm{Dg}$ with monomer concentration of 5 and $10 \%$ at $40^{\circ} \mathrm{C}$. The Dg increased with increment of the reaction time. And the Dg becomes 2 times higher with the increase of monomer concentration from $5 \%$ to $10 \%$. The $\mathrm{Dg}$ of $130 \%$ was obtained at monomer concentration of $5 \%$ for 2 hours which is satisfied the requirements for preparing As(V) adsorbent. Therefore, it was concluded that the

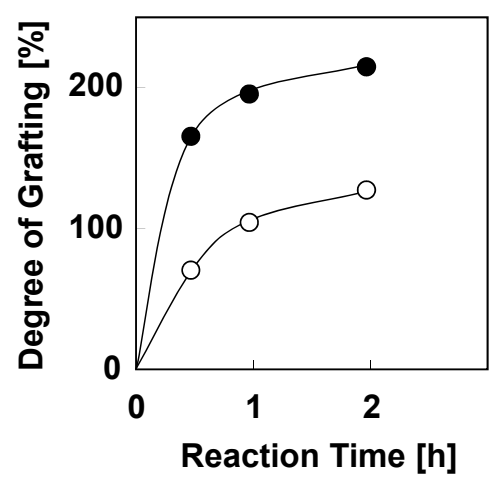

Figure 2. Effect of reaction time on Dg with monomer concentration of $(O) 5 \%$ and $(O) 10 \%$ at $40^{\circ} \mathrm{C}$. 
optimum graft condition of phosphoric acid monomer is monomer concentration of $5 \%$ on the reaction time of 2 hours at reaction temperature of $40^{\circ} \mathrm{C}$. In comparison with a graft polymerization using polyethylene as a trunk polymer [14], cotton-grafting could be reduce monomer concentration, reaction time, reaction temperature and irradiation dose, which indicates that the cotton-grafting is effective and economical to introduce a phosphoric acid monomer onto trunk polymer. Surface of cotton fabric was observed with scanning electron microscope [SEMEDX Type N, HITACHI]. SEM photographs of cotton fabric before and after grafting were shown in Figure 3. After grafting for 2 hours, the diameter increased from $12 \mu \mathrm{m}$ to $20 \mu \mathrm{m}$, and the damage from grafting did not appear on surface of the cotton fabric.

\subsection{Loading of Zirconium on Phosphoric Units}

The $\mathrm{Zr}(\mathrm{IV})$ loading on phosphoric units was carried out by pumping $10 \mathrm{mmol} / \mathrm{L}$ of $\mathrm{Zr}(\mathrm{IV})$ solution into the grafted material-packed column at SV200 $\mathrm{h}^{-1}$. Figure 4 shows the characterization of $\mathrm{Zr}(\mathrm{IV})$ loading. Almost of all $\mathrm{Zr}(\mathrm{IV})$ was loaded on phosphoric units around $10 \mathrm{BV}$. As a result, $0.38 \mathrm{mmol} / \mathrm{g}$ of $\mathrm{Zr}(\mathrm{IV})$ was loaded on the grafted material by $50 \mathrm{BV}$ feeding at $\mathrm{pH} 1$. The maximum $\mathrm{Zr}(\mathrm{IV})$ density at $\mathrm{pH} 2$ was $0.31 \mathrm{mmol} / \mathrm{g}$, which is lower than the value obtained at $\mathrm{pH} 1$. Hence, the $\mathrm{Zr}(\mathrm{IV})$ loading was performed at $\mathrm{pH} 1$.

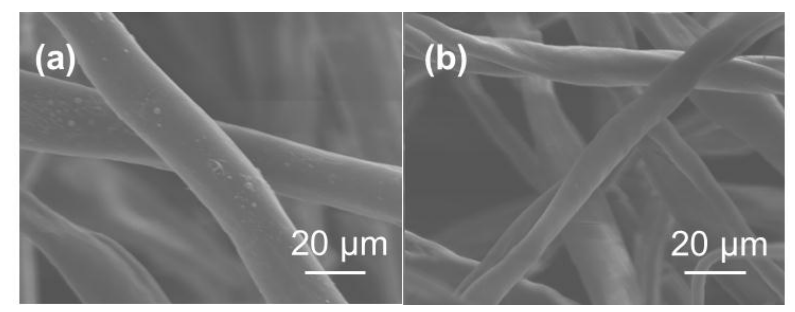

Figure 3. SEM photographs of (a) trunk polymer and (b) grafted polymer of $130 \%$.

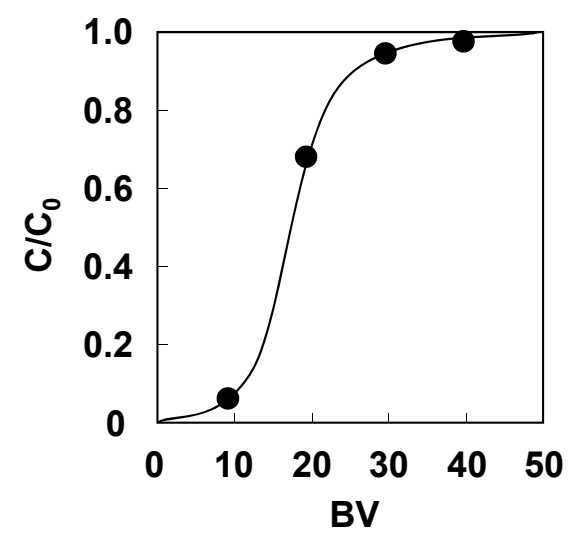

Figure 4. Zirconium(IV) loading on phosphoric units with $10 \mathrm{mmol} / \mathrm{L}$ of $\mathrm{Zr}(\mathrm{IV})$ solution on $\mathrm{SV} 200 \mathrm{~h}^{-1}$ at $\mathrm{pH} 1$.

\subsection{Column Mode Adsorption of Arsenic}

Column mode adsorption of $\mathrm{As}(\mathrm{V})$ was performed with 1 $\mathrm{mg} / \mathrm{L}$ of $\mathrm{As}(\mathrm{V})$ solution. The breakthrough curves of $\mathrm{As}(\mathrm{V})$ adsorption at various $\mathrm{pH}$ with $\mathrm{SV} 200 \mathrm{~h}^{-1}$ is shown in Figure 5. The adsorbent can adsorb $\mathrm{As}(\mathrm{V})$ across a wide range of $\mathrm{pH}$ values. The $\mathrm{BV}$ at breakthrough point were $870,1420,900,550,330$ and 270 at $\mathrm{pH} \mathrm{1,} \mathrm{2,} \mathrm{3,} \mathrm{5,} 7$ and 9, respectively. The maximum capacity of $\mathrm{As}(\mathrm{V})$ adsorption was $0.1 \mathrm{mmol} / \mathrm{g}$ at $\mathrm{pH}$ 2. At $\mathrm{pH}$ range of higher than 3, As(V) capacity of the adsorbent signifycantly decreased with increment of $\mathrm{pH}$, and also decreased slightly at $\mathrm{pH} 1$. Therefore, the effect of flow rate on $\mathrm{As}(\mathrm{V})$ adsorption was investigated at $\mathrm{pH} 2$.

Figure 6 shows the breakthrough curves of $\mathrm{As}(\mathrm{V})$ adsorption with $\mathrm{As}(\mathrm{V})$ solution of $1 \mathrm{mg} / \mathrm{L}$ at $\mathrm{SV} 200$ and $1000 \mathrm{~h}^{-1}$. The adsorption capacity for $\mathrm{As}(\mathrm{V})$ was 0.1 $\mathrm{mmol} / \mathrm{g}$ with either flow rate. Increasing the flow rate up to SV $1000 \mathrm{~h}^{-1}$ did not have significant effect on the adsorption capacity of $\mathrm{As}(\mathrm{V})$. In general, the granular resin adsorbent is effective for $\mathrm{As}(\mathrm{V})$ adsorption at relatively slow flow rate around SV $10 \mathrm{~h}^{-1}[7]$. It means that the fibrous adsorbent, which was synthesized by RIGP, can adsorb As(V) 100 times faster than granular resin.

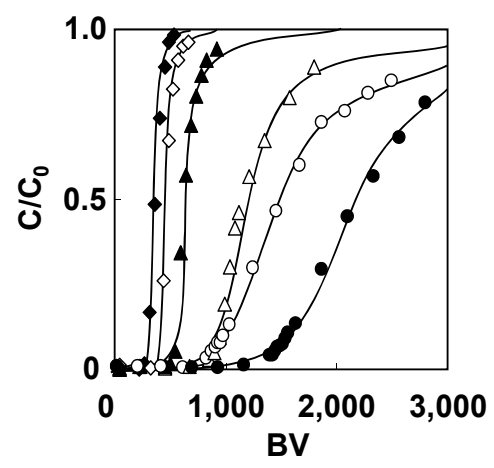

Figure 5. Breakthrough curves of $\mathrm{As}(\mathrm{V})$ adsorption with 1 $\mathrm{mg} / \mathrm{L} \mathrm{As}(\mathrm{V})$ solution on $\mathrm{SV} 200 \mathrm{~h}^{-1}$ at various $\mathrm{pH}$. (O) pH 1 , $(\odot)$ pH 2, $(\triangle)$ pH 3, (A) pH 5, $\diamond)$ pH 7 and $(\diamond)$ pH 9.

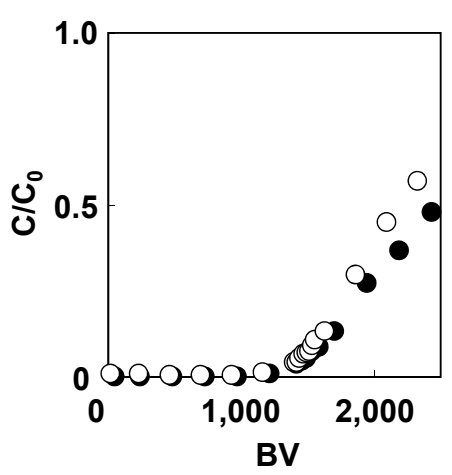

Figure 6. Effect of flow rate on $\mathrm{As}(\mathrm{V})$ adsorption with 1 $\mathrm{mg} / \mathrm{L} \mathrm{As}(\mathrm{V})$ solution at pH 2 on $(\mathrm{O})$ SV200 h-1 and (O) $\mathrm{SV} 1000 \mathbf{h}^{-1}$. 


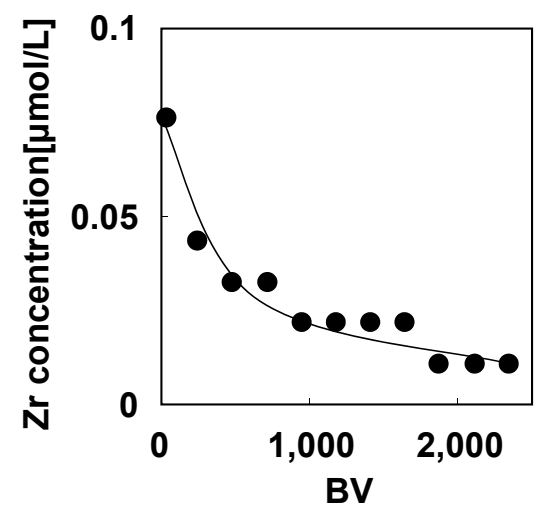

Figure 7. Zirconium(IV) dissolution from the adsorbent during the $\mathrm{As}(\mathrm{V})$ adsorption with $1 \mathrm{mg} / \mathrm{L}$ of $\mathrm{As}(\mathrm{V})$ solution on SV $200 \mathrm{~h}^{-1}$ at pH 2.

\subsection{Stability of the Zr-Type Adsorbent}

The loaded $\mathrm{Zr}(\mathrm{IV})$ should be hold on phosphoric units in stable condition during the adsorption. The evaluation of the stability of the Zr-type adsorbent was carried out by monitoring the $\mathrm{Zr}(\mathrm{IV})$ dissolution from the adsorbent during the $\mathrm{As}(\mathrm{V})$ adsorption with $1 \mathrm{mg} / \mathrm{L}$ of $\mathrm{As}(\mathrm{V})$ solution on SV $200 \mathrm{~h}^{-1}$ at $\mathrm{pH}$ 2. The result was shown in Figure 7. The concentration of $\mathrm{Zr}(\mathrm{IV})$ was $0.08 \mu \mathrm{mol} / \mathrm{L}$ at $\mathrm{BV}$ of 20 and then gradually decreased to $0.01 \mu \mathrm{mol} / \mathrm{L}$.

The total amount of $\mathrm{Zr}(\mathrm{IV})$ dissolution from the adsorbent was $0.014 \mu \mathrm{mol}$, which correspond to $0.05 \%$ of the loaded $\mathrm{Zr}(\mathrm{IV})$ on the adsorbent. This result indicates that $\mathrm{Zr}(\mathrm{IV})$ is retained on the adsorbent stably.

\section{Conclusion}

The zirconium(Zr)-type adsorbent using a nonwoven cotton fabric as a trunk polymer was successfully prepared by RIGP with low concentration of phosphoric monomer solution (5\%) at low irradiation dose (20 kGy) for short reaction time ( 2 hours) and was subsequently modified with $\mathrm{Zr}$ (IV) by loading on phosphoric units. The adsorption capacity of the adsorbent for $\mathrm{As}(\mathrm{V})$ was $0.1 \mathrm{mmol} / \mathrm{g}$ with $\mathrm{SV} 1000 \mathrm{~h}^{-1}$ at $\mathrm{pH} 2$. The adsorption rate of the adsorbent was 100 times faster than that of granular resin. The dissolution of $\mathrm{Zr}(\mathrm{IV})$ from the adsorbent was negligible on As(V) adsorption.

\section{Acknowledgements}

This research was supported by Adaptable and Seamless Technology transfer Program of Japan Science and Technology Agency.

\section{REFERENCES}

[1] P. L. Smedley and D. G. Kinniburgh, "A Review of the Source, Behaviour and Distribution of Arsenic in Natural Water," Applied Geochemistry, Vol. 17, No. 5, 2002, pp.
517-568. doi:10.1016/S0883-2927(02)00018-5

[2] P. Ravenscroft, "Arsenic Pollution of Groundwater in Bangladesh," Encyclopedia of Environmental Health, 2011, pp. 181-192.

http://www.sciencedirect.com/science/article/pii/B978044 4522726003470

[3] Y. Kikawada, S. Kawai, K. Shimada and T. Oi, "Origin and Fate of Dissolved Arsenic in Acidic Rivers in the Kusatsu Hot Spring Area, Gunma, Japan," Geochimica et Cosmochimica Acta, Vol. 70, No. 18, 2006, p. 317. doi:10.1016/j.gca.2006.06.640

[4] B. K. Mandal and K. T. Suzuki, "Arsenic round the World: A Review," Talanta, Vol. 58, No. 1, 2002, pp. 201-235. doi:10.1016/S0039-9140(02)00268-0

[5] C. Hu, H. Liu, G. Chen and J. Qu, "Effect of Aluminum Speciation on Arsenic Removal during Coagulation Process," Separation and Purification Technology, Vol. 86, No. 2012, pp. 35-40. doi:10.1016/j.seppur.2011.10.017

[6] C. Lenoble, C. Chabroullet, R. Shukry, B. Serpaud, V. Deluchat and J. C. Bollinger, "Dynamic Arsenic Removal on a $\mathrm{MnO}_{2}$-Roaded Resin," Journal of Colloid and Interface Science, Vol. 280, No. 1, 2004, pp. 62-67. doi:10.1016/j.jcis.2004.07.034

[7] T. M. Suzuki, J. O. Bomani, H. Matsunaga and T. Yokoyama, "Preparation of Porous Resin Loaded with Crystalline Hydrous Zirconium Oxide and Its Application to the Removal of Arsenic," Reactive \& Functional Polymers, Vol. 43, No. 1-2, 2000, pp. 165-172. doi:10.1016/S1381-5148(99)00038-3

[8] Y. M. Zheng, S. F. Lim and J. P. Chen, "Preparation and Characterization of Zirconium-Based Magnetic Sorbent for Arsenate Removal," Journal of Colloid and Interface Science, Vol. 338, No. 1, 2009, pp. 22-29.

doi:10.1016/j.jcis.2009.06.021

[9] M. Tamada, N. Seko and F. Yoshii, "Application of Radiation-Graft Material for Metal Adsorbent and Crosslinked Natural Polymer for Healthcare Product," Radiation Physics and Chemistry, Vol. 71, No. 1-2, 2004, pp. 221-225. doi:10.1016/j.radphyschem.2004.03.044

[10] K. Saito, S. Yamada, S. Furusaki, T. Sugo and J. Okamoto, "Characteristics of Uranium Adsorption by Amidoxime Membrane Synthesized by Radiation-Induced Graft Polymerization," Journal of Membrane Science, Vol. 34, No. 3, December 1987, pp. 307-315. doi:10.1016/S0376-7388(00)83171-3

[11] N. Seko, H. Hoshina, N. Kasai, Y. Ueki, M. Tamada, T. Kiryu, K. Tanaka and M. Takahashi, "Novel System for Recovering Scandium from Hot Spring Water with Fibrous Graft Adsorbent," Journal of Ion Exchange, Vol. 21, No. 3, 2010, pp. 117-122.

[12] H. Hoshina, N. Seko, Y. Ueki and M. Tamada, "Synthesis of Graft Adsorbent with N-Methyl-D-glucamine for Boron Adsorption," Journal of Ion Exchange, Vol. 18, No. 4, 2007, pp. 236-239. doi:10.5182/jaie.18.236

[13] H. Ma, K. Morita, H. Hoshina and N. Seko, "Synthesis of Amine-Type Adsorbents with Emulsion Graft Polymerization of 4-Hydroxybutyl Acrylate Glycidylether," Materials Sciences and Applications, Vol. 2, No. 7, 2011, pp. 
776-784. doi:10.4236/msa.2011.27107

[14] F. Basuki, N. Seko, M. Tamada, T. Sugo and T. Kume, "Direct Synthesis of Adsorbent Having Phosphoric Acid with Radiation Induced Graft-Polymerization," Journal of Ion Exchange, Vol. 14, 2003, pp. 209-212.

doi:10.5182/jaie.14. Supplement 209 